\title{
Metabolome profile of osmotolerant rhizobacteria under osmotic stress
}

\author{
T A Surya ${ }^{1}$, O Palupi $^{1}$, T Yuwono $^{1}$, Ngadiman $^{1}$, and S Wedhastri ${ }^{1}$ \\ ${ }^{1}$ Department of Agricultural Microbiology, Faculty of Agriculture, \\ Universitas Gadjah Mada, Yogyakarta, Indonesia \\ Corresponding author, e-mail: triwibowo_y@ugm.ac.id
}

\begin{abstract}
An osmotolerant rhizobacteria (Enterococcus flavescens), isolated from the weed rhizosphere, has been subjected to osmotic stress in broth media supplemented with varied concentrations of glucose and sodium chloride $(\mathrm{NaCl})$. The aims of this work was to evaluate the cells' response and obtain a comprehensive view of metabolites profiles under osmotic stress. Cells were grown in rich medium (Luria Bertani, LB) supplemented with $\mathrm{NaCl}$ at varying concentrations $(0.5 \mathrm{M}-1.8 \mathrm{M} \mathrm{NaCl})$ and glucose $(5 \%-20 \%)$, both as a single or double stress condition. Physiological response was observed by measuring rhizobacterial growth and analysing metabolite synthesised using GC-MS. The results of this study demonstrated that different concentration of salt and glucose resulted in different metabolite profiles. It was also observed that cells cultivated in $\mathrm{LB}+1,6 \mathrm{M}$ $\mathrm{NaCl}$ and $\mathrm{LB}+1,8 \mathrm{M} \mathrm{NaCl}$ medium resulted in only two different compounds detected, i.e amide and fatty acid. Under double stress, however, concentration of hexadecanoic acid, hexadecenoic acid, proline and glycerin was found increased, while under single-salt and glucose stress, hexadecanoic acid and 9- octadecenoic acidmethyl ester were detected. Those two acid were absent from the cells' metabolites under double stress. The results of this study thus suggested that osmotic stress provokes different pathway of fatty acid metabolism. The metabolome profile of the rhizobacteria under stress condition may also reveal specific mechanism of microbial tolerance to osmotic stress under different condition. The possible mechanism and pathway of osmotic stress in microorganisms will be discussed.
\end{abstract}

Keywords: osmotolerant rhizobacteria, metabolome, osmotic stress

\section{INTRODUCTION}

Environmental stress, such as osmotic and salt stress, has become a major issue in agricultural practices as it may hamper the plant cultivation and production. Soil salinity is a global and the most important issue in agriculture as it turns the agricultural land into unproductive areas about 1-2 $\%$ a year in arid and semi-arid zones. Salinity limits plant growth and development which in turn decreases plant production [1]. The use of plant growth promoting rhizobacteria (PGPR) for the improvement of plant growth and development has become a significant approach. In certain cases, such as in banana (Musa acuminata) plantation, the inoculation of banana with Bacillus amyloliquefaciens and Pseudomonas fluorescens resulted in improved plant growth and altered the metabolome profile of the plant [2]. It was also observed that halotolerant bacteria Kosakonia radicincitans increased root-colonising capability and improved growth of radish plant [3]. The use plant growth promoting rhizobacteria, Bacillus subtilis, B. amyloliqufaciens, B. cereus, Pseudomonas putida, and P. fluorescens, were also shown to reduce the damage of tomato root by nematode [4]. Similarly, osmotolerant rhizobacteria has also been shown to improve rice growth under drought stress [5].

It is interesting to note that banana plant metabolome profile [2] altered when inoculated with halotolerant bacteria. Cytoplasmic membrane fluidity and fatty acid composition of 
Acidithiobacillus ferrooxidans also changed when subjected to $\mathrm{pH}$ stress [6] suggesting that membrane permeability was compromised under extreme acidity ( $\mathrm{pH} 1.5$ ). It was also found that Dunaliella salina cultivated under high $\mathrm{NaCl}$ stress $(1.5 \mathrm{M})$ demonstrated the increase of 9,12,15octadecatrienoic acid (Z,Z,Z) (C18:3 ${ }^{\Delta 9,12,15}$ ) synthesis [7]. Similarly, in Chlamydomonas reinhardtii the synthesis of octadecatrienoic acid (C18:3) dan octadecadienoic acid (C18:2) also increased under $\mathrm{NaCl}$ stress [8]. In Saccharomyces cerevisiae, salt $(\mathrm{NaCl})$ stress also resulted in the abundant synthesis of cis-9-hexadecanoic acid $\left(\mathrm{C} 16: 1^{\Delta 9}\right)$ which constitute $10-30 \%$ of the whole fatty acids [9].

In the work presented here we demonstrated and discussed the changes of metabolome profile. Our work demonstrated that osmotolerant rhizobacteria (Enterococcus flavescens), isolated from the weed rhizosphere, showed altered composition of fatty acid under single or double stress, suggested that osmotic stress provokes different metabolic pathway.

\section{MATERIALS AND METHODS}

\subsection{Cell cultivation}

Cells of Enterococcus flavescens were cultivated in Luria Bertani medium supplemented with 0,$5 ; 1$; 1,$5 ; 1,8 \mathrm{M}$ concentrations of $\mathrm{NaCl}$ and glucose at $5,10,15$, dan $20 \%$ concentrations. Cells were incubated at $30^{\circ} \mathrm{C}$ with shaking for 76 hours. Samples of cells were drawn in 4 hours period for growth analysis and metabolites extraction and analysis.

\subsection{Metabolite cell extraction}

Fifty $\mathrm{ml}$ of cells grown under $\mathrm{NaCl}$ and/or glucose stress were harvested by centrifugation. Cell pellets were centrifuged at $10,000 \mathrm{~g}$ for 10 minutes. Cell pellets were then suspended in cold methanol and sonicated until the cells were broken up. Following sonication, cell suspension was kept at $-80^{\circ} \mathrm{C}$ for 24 hours. After incubation, cell suspension was centrifuged at $10,000 \mathrm{~g}$ for $10 \mathrm{~min}$. Cell pellet was then discarded, and the supernatant was used for analysis using GC-MS.

\subsection{Gas Chromatogaph-Mass Spectrometry (GC-MS).}

Analysis of metabolites in the cell pellets was carried out by using GCMS-QP2010S SHIMADZU. Helium was used as the carrier gas, column temperature $70^{\circ} \mathrm{C}$. Samples were injected into the column at initial temperature of $70^{\circ} \mathrm{C}$ and a maximum of $300^{\circ} \mathrm{C}$ with splitless mode.

\section{RESULTS AND DISCUSSION}

\subsection{Growth of E. flavescens under $\mathrm{NaCl}$ and glucose stress}

Previous finding [10] suggested that rhizospheres of alfafa (Medicago sativa) plants exposed to differing watering-limiting conditions harbour distinct bacterial communities. It is interesting to see whether osmotic stress imposed by $\mathrm{NaCl}$ and glucose, which may also reflect water scarcity, changes rhizobacterial metabolites. Different response to osmotic stress may suggest the relationship between the bacterial population thrive in certain niche with their ability to withstand the environmental stress. In this study we found that, under different stress conditions, E. flavescens showed growth response (Figure 1) that reflects the shift in the metabolic pattern. It was observed that $\mathrm{NaCl}$ gave a more striking effect on growth of $E$. flavescens than glucose as evidenced by the fact that cells underwent longer adaptation under $\mathrm{NaCl}$ stress (Figure 1A). It is interesting to note that under double stress, glucose present in the medium, albeit at high concentration, reduced the stress effect of $\mathrm{NaCl}$ (Figure 1B) at higher concentration. Growth of cells under single, $1.8 \mathrm{M} \mathrm{NaCl}$, was lower than growth under double stress $(1.8 \mathrm{M} \mathrm{NaCl}$ $+15 \%$ glucose), suggesting that glucose may compensate the effect of $\mathrm{NaCl}$ at high concentration. 

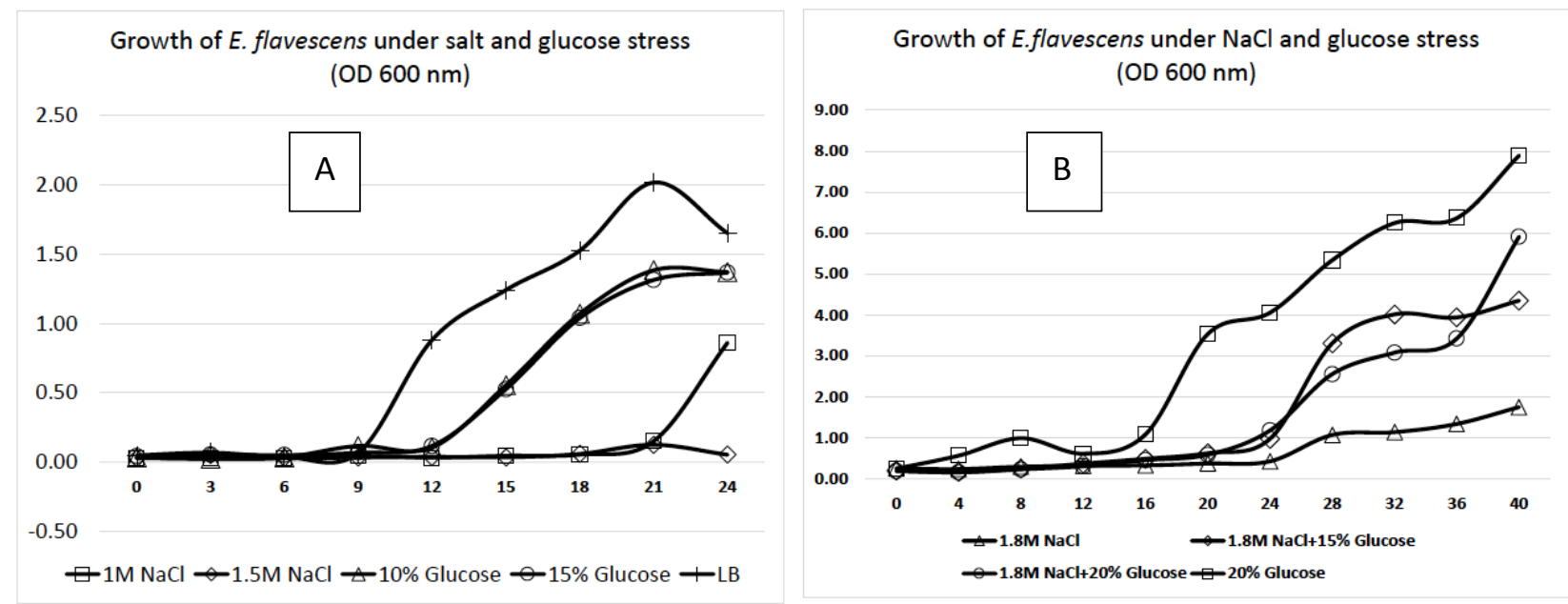

Figure 1. Growth of E. flavescens under different $\mathrm{NaCl}$ and glucose stress. A: $1 \mathrm{M} \mathrm{NaCl}$ and $1.5 \mathrm{M} \mathrm{NaCl}, 10 \%$ and $15 \%$ glucose; $\mathrm{B}: 1.8 \mathrm{M} \mathrm{NaCl}, 20 \%$ glucose.

\subsection{Metabolite profiles of E. flavescens under $\mathrm{NaCl}$ and glucose stress}

Cells of E. flavescens grown under $\mathrm{NaCl}$ and glucose stress were extracted and analysed using GC-MS to reveal metabolites synthesised under certain stress condition (Figure 2). It was observed that several compounds were found in cells under all stress conditions, i.e.: Cholesteryl myristate; Pentadecanoic acid; 14-methyl-, methyl ester; 11 Octadecenoic acid, methyl ester; and Dodecanoic acid. However, different stress condition resulted in the synthesis of different metabolites. It was observed that, several compounds were only detected when the cells were grown under single stress $(1.8 \mathrm{M} \mathrm{NaCl}$ or $15 \%$ glucose), i.e.: 9Octadecenoic acid, methyl ester; Butanedioic acid, 2,3-dimethoxy-, dimethyl ester; 6- Octadecenoic acid, methyl ester; 2-Dodecenyl(-)succinic anhydride; Oxiraneundecanoic acid, 3-pentyl-, methyl ester, cis-; 4-Piperidinamine, N,1-dimethyl-;
Glycerin; Phenylethylamine; 2,6,10-Dodecatrienol, 3,7,11-trimethyl-; Butyrolactone; Germacrene B; Cyclopropanedodecanoic acid, 2-octyl-, methyl ester; delta.-Guaiene; Glycolic acid, methyl ester; and Carbamic acid, methyl ester.

Under double stress $(1.8 \mathrm{M} \mathrm{NaCl}+15 \%$ glucose), 17 compounds were detected which fall into groups of aldehyde, alkana, alcohol, amide, fatty acids, lipid, terpene, while under single stress the metabolites synthesis were mostly lipid, fatty acids, amine, and amide. These compounds: Decanedioic acid, ethyl decenoate phthalic acid, tridecane, tridecanoate, undecane, decanedione, decenol, hexylvinyl sulfide, dioxolanone, L-Proline, heptanone, pentanone, aminopropanol, glycolic acid, carbamic acid, Glycerin, dodecanetrienol, dodecenyl, germacrene, dan azulene were detected under double stress of $1.8 \mathrm{M} \mathrm{NaCl}+15 \%$ glucose, suggesting that metabolites may be grouped into fatty acids, osmoprotectant, and other compounds. 


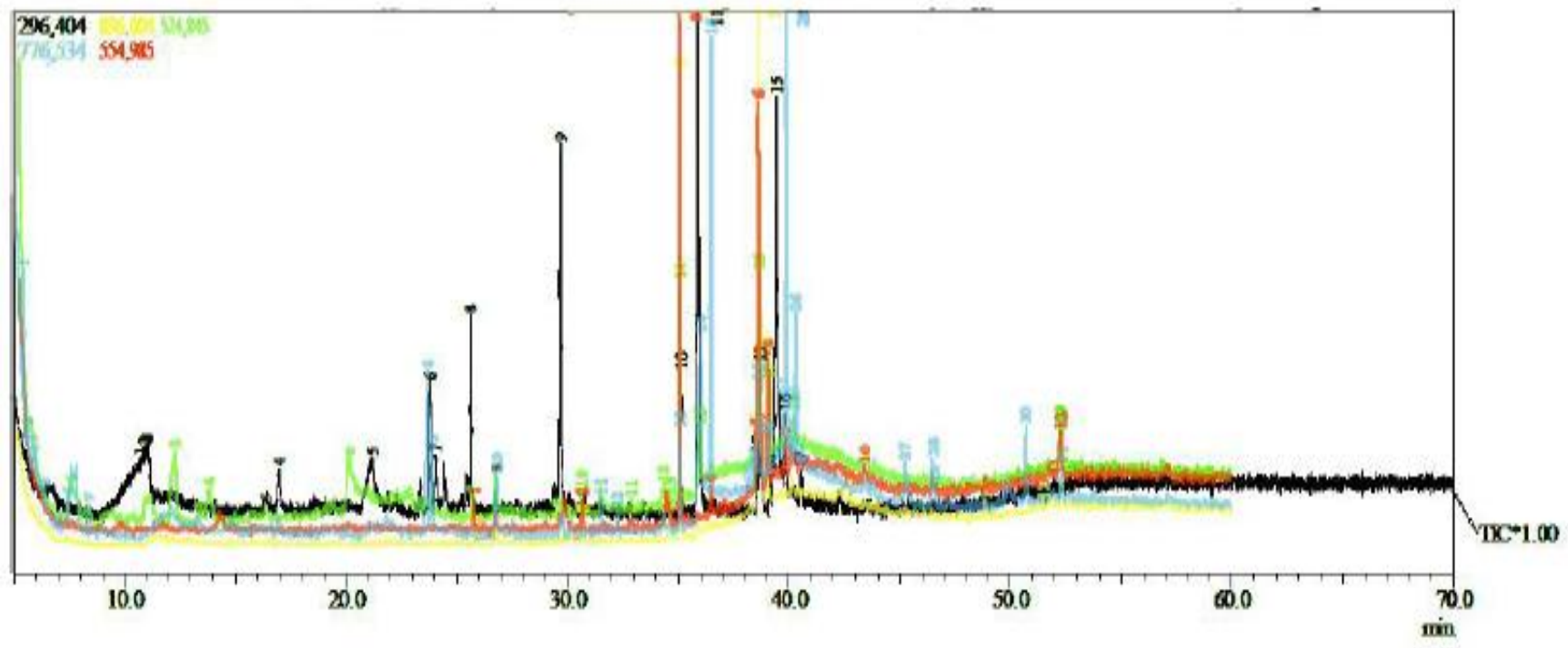

Figure 2. Metabolites profiles of E. flavescens under $\mathrm{NaCl}$ and glucose stress. Cells were grown in medium $\mathrm{LB}$ (green); $1.8 \mathrm{M} \mathrm{NaCl}+15 \%$ glucose (black) $1.8 \mathrm{M} \mathrm{NaCl}+15 \%$ glucose (extracted using diethyl ether) (blue); $15 \%$ glucose (red); $1.8 \mathrm{M} \mathrm{NaCl}$ (yellow).

Other interesting finding was that metabolites oxirane and propylheptanol were detected only under single stress imposed by $1.8 \mathrm{M} \mathrm{NaCl}$, while piperidinamine was detected only under $15 \%$ glucose and not in other stress conditions. It was also found that under non-stress condition (in LB medium), most of the metabolites synthesised were of long chain of alkana (C14 - C44) and alkena (C21 - C44). Under single stress $(\mathrm{NaCl})$, most of the metabolites were of medium chain length of fatty acids (C13 and $\mathrm{C} 18)$. The changes of metabolite profiles of E. flavescens under $\mathrm{NaCl}$ and glucose stress suggest the shift of metabolic pathway of fatty acids, as found in Saccharomyces cerevisiae [9], Dunaliella salina [7], and Chlamydomonas reinhardtii [8].

Under non-stress condition, concentration of fatty acids reached $46 \%$ consists of fatty acids with $\mathrm{C} 10$ to $\mathrm{C} 25$. On the other hand, under single stress ( $\mathrm{NaCl}$ or glucose) condition, fatty acids of $\mathrm{C} 10$ to C12 were synthesised abundantly up to $92.5 \%$, while under double stress fatty acids lowered to $62.8 \%$ of $\mathrm{C} 11$ to $\mathrm{C} 25$. This observation suggests that under stress condition, E. flavescens increased the synthesis of long chain fatty acids. The increase and accumulation of long chain fatty acids helps the cells in responding to osmotic stress and changes cell membrane permeability and fluidity [11]. The lower fatty acid concentration under double stress than under non-stress may be attributed to the fact that under double stress, the cells shifted its metabolic pathway to synthesis other compounds. It was also found that decomposition derivatives of fatty acids, 3- (Chloromethyl)heptane; 2Ethylbutyraldehyde; 3,3-dimethyl-Pentane; 4methyl-1,3-Dioxolanone; 3-Decenol; and methyl heptanone, were detected under double stress condition. It is interesting to note that Bambara garoundnut rhizobacteria synthesised several volatile compounds that demonstrated antibacterial activity [12].

In addition to changes of the composition of fatty acids, alkena, alcohol, amide, ketone were among compounds synthesised by cells under different stress (Table 1). Interestingly it was observed that osmoprotectant compounds were detected only in the cells subjected to double stress $(\mathrm{NaCl}$ and glucose). This observation clearly suggests the metabolic pathway shift occurred in the cells under double stress by synthesising osmoprotectant to ease the environmental pressure. It is, therefore, of interest to pursue further the implication of environmental pressure on the metabolic pathway of the cells, not only in microbial cells but also in higher cells. 
Table 1. Several compounds other than fatty acids synthesised under stress.

\begin{tabular}{|c|c|c|c|c|}
\hline $\begin{array}{c}\text { Compou } \\
\text { nds }\end{array}$ & $1,8 \mathrm{M} \mathrm{NaCl}+15 \%$ Glucose & $1,8 \mathrm{M} \mathrm{NaCl}$ & $\begin{array}{c}15 \% \\
\text { Glucose }\end{array}$ & LB \\
\hline Alkena & $\begin{array}{l}\text { 1H-Cycloprope azulene, } \\
\text { decahydro-1,1,7-trimethyl-4- } \\
\text { methylene }\end{array}$ & ND & ND & ND \\
\hline Alcohol & $\mathrm{ND}$ & 2-Propylheptanol & ND & $\begin{array}{l}\text { Hexadecanol } \\
\text { Phenylethyl Alcohol }\end{array}$ \\
\hline Amide & ND & & 9-Octadecenamide & 9-Octadecenamide \\
\hline Ketone & ND & ND & ND & $\begin{array}{l}\text { Dihydro-2(3H)- } \\
\text { Furanone }\end{array}$ \\
\hline & & & & $\begin{array}{l}2,8,4,6- \\
\text { (Epoxyethanediylid } \\
\text { enoxy) } \\
1,3 \text { dioxino }\end{array}$ \\
\hline $\begin{array}{l}\text { Osmopro } \\
\text { tectant }\end{array}$ & $\begin{array}{l}\text { Glycerin } \\
\text { Germacrene B } \\
\text { delta.-Guaiene }\end{array}$ & ND & ND & $\mathrm{ND}$ \\
\hline \multirow[t]{11}{*}{$\begin{array}{l}\text { Miscella } \\
\text { neous }\end{array}$} & \multirow[t]{4}{*}{$\begin{array}{l}2,8,4,6- \\
\text { (Epoxyethanediylidenoxy) } \\
1,3 \text { dioxino }\end{array}$} & ND & ND & $\begin{array}{l}2,8,4,6- \\
\text { (Epoxyethanediylid } \\
\text { enoxy) } \\
1,3 \text { dioxino }\end{array}$ \\
\hline & & \multirow[t]{3}{*}{$\begin{array}{l}\text { Cholesteryl } \\
\text { myristate }\end{array}$} & \multirow[t]{3}{*}{$\begin{array}{l}\text { Cholesteryl } \\
\text { myristate }\end{array}$} & $\begin{array}{l}\text { Cholesteryl } \\
\text { myristate }\end{array}$ \\
\hline & & & & Aziridine, 2-ethyl- \\
\hline & & & & $\begin{array}{l}\text { Aziridine, 2-heptyl- } \\
\text { 3-methyl- }\end{array}$ \\
\hline & 2-Dodecenvl(-)succinic & Oxiraneundecan & 4-Piperidinamine, & Piperazine (CAS) \\
\hline & anhydride & $\begin{array}{l}\text { pentyl-, methyl } \\
\text { ester, cis- (C19) }\end{array}$ & & \\
\hline & & ND & ND & Phenylethylamine \\
\hline & Carbamic acid, methyl ester & & & \\
\hline & $\begin{array}{l}\text { 2,6,10-Dodecatrienol, } \\
\text { 3,7,11-trimethyl- }\end{array}$ & ND & ND & Butyrolactone \\
\hline & Piperazine (CAS) R22 & ND & ND & $\begin{array}{l}\text { Cyclopropanedode } \\
\text { canoic acid, 2- } \\
\text { octyl-, methyl } \\
\text { ester (C24) }\end{array}$ \\
\hline & Glycolic acid, methyl ester & ND & ND & $\mathrm{ND}$ \\
\hline
\end{tabular}

ND: not detected

Data presented in this study thus provide an insight to the complexity of cellular metabolism under environmental stress which is reflected on the growth pattern as well as the metabolism shift. Changes in fatty acids composition are not the sole implication of the metabolic shift as it was observed 
that other compounds, including osmoprotectants were also synthesised under certain stress condition.

\section{CONCLUSION}

The results of this study demonstrated that osmotolerant rhizobacteria, Enterobacter flavescens, responded differently in terms of its metabolites synthesised under different stress conditions ( $\mathrm{NaCl}$ and glucose stress) as evidenced by the appearance of specific metabolites under specific stress condition, suggesting that different stress provokes metabolic shift.

\section{ACKNOWLEDGMENT}

The present paper was part of the research grant project awarded to Triwibowo Yuwono through PDUPT Project Basic Research, contract number 2636/UN1.DITLIT/DIT-LIT/LT/2019 administered by Universitas Gadjah Mada, Yogyakarta, Indonesia

\section{REFERENCES}

[1] Etesami H, Maheshwari DK. Use of plant growth promoting rhizobacteria (PGPRs) with multiple plant growth promoting traits in stress agriculture: Action mechanisms and future prospects. Ecotoxicol Environ Saf. 2018;156:225-46.

[2] Gamez RM, Rodriguez F, Vidal NM, Ramirez S, Vera Alvarez R, Landsman D, et al. Banana (Musa acuminata) transcriptome profiling in response to rhizobacteria: Bacillus amyloliquefaciens Bs006 and Pseudomonas fluorescens Ps006. BMC Genomics. 2019;20(1):378.

[3] Cruz Barrera M, Jakobs-Schoenwandt D, Gomez MI, Becker M, Patel AV, Ruppel S. Salt stress and hydroxyectoine enhance phosphate solubilisation and plant colonisation capacity of Kosakonia radicincitans. J Adv Res. 2019;19:91-7.

[4] Almaghrabi OA, Massoud SI, Abdelmoneim TS. Influence of inoculation with plant growth promoting rhizobacteria (PGPR) on tomato plant growth and nematode reproduction under greenhouse conditions. Saudi J Biol Sci. 2013;20(1):57-61.

[5] Yuwono T, Handayani D, Soedarsono J. The role of osmotolerant rhizobacteria in rice growth under different drought conditions. Australian Journal of Agricultural Research. 2005;56(7):715-21.

[6] Mykytczuk NC, Trevors JT, Ferroni GD, Leduc LG. Cytoplasmic membrane fluidity and fatty acid composition of Acidithiobacillus ferrooxidans in response to pH stress. Extremophiles. 2010;14(5):427-41.

[7] Rismani S, Shariati M. Changes of the Total Lipid and Omega-3 Fatty Acid Contents in two Microalgae Dunaliella Salina and Chlorella Vulgaris Under Salt Stress. Brazilian Archives of Biology and Technology. 2017;60.

[8] Hounslow E, Kapoore RV, Vaidyanathan S, Gilmour DJ, Wright PC. The Search for a Lipid Trigger: The Effect of Salt Stress on the Lipid Profile of the Model Microalgal Species Chlamydomonas reinhardtii for Biofuels Production. Curr Biotechnol. 2016;5(4):30513.

[9] Turk M, Mejanelle L, Sentjurc M, Grimalt JO, Gunde-Cimerman N, Plemenitas A. Saltinduced changes in lipid composition and membrane fluidity of halophilic yeast-like melanized fungi. Extremophiles. 2004;8(1):53-61.

[10] Bogino P, Abod A, Nievas F, Giordano W. Water-limiting conditions alter the structure and biofilm-forming ability of bacterial multispecies communities in the alfalfa rhizosphere. PLoS One. 2013;8(11):e79614.

[11] Singh JS. Plant Growth Promoting Rhizobacteria. Resonance. 2013;18(3):275-81.

[12] Ajilogba CF, Babalola OO. GC-MS analysis of volatile organic compounds from Bambara groundnut rhizobacteria and their antibacterial properties. World J Microbiol Biotechnol. 2019;35(6):83. 